\title{
TITLE:
}

\section{Control of polymorphic transition inducing preferential enrichment}

$\operatorname{AUTHOR}(S)$ :

Tamura, Rui; Iwama, Sekai; Gonnade, Rajesh G.

\section{CITATION:}

Tamura, Rui ...[et al]. Control of polymorphic transition inducing preferential enrichment. CrystEngComm 2011, 13(17): 5269-5280

ISSUE DATE:

2011-05

URL:

http://hdl.handle.net/2433/157361

\section{RIGHT:}

(c) Royal Society of Chemistry 2011; この論文は出版社版でありません 。引用の際には出版社版をご確認ご利用ください。; This is not the published version. Please cite only the published version. 
Control of polymorphic transition inducing preferential enrichment

Rui Tamura, Sekai Iwama, and Rajesh G. Gonnade

\begin{abstract}
Preferential enrichment is an unusual symmetry-breaking enantiomeric resolution phenomenon that is initiated by the solvent-assisted solid-to-solid transformation of a metastable polymorphic form into a thermodynamically stable one during crystallization from the supersaturated solution of a certain kind of racemic crystals. On the basis of the proposed mechanism of preferential enrichment, both induction and inhibition of preferential enrichment were successfully achieved by controlling the mode of the polymorphic transition during crystallization either by minor molecular modification or with appropriate seed crystals. Furthermore, by inducing a desired polymorphic transition during crystallization of several $\alpha$-amino acids or their cocrystals with dicarboxylic acids, which were classified as a racemic compound, preferential enrichment could also be accomplished.
\end{abstract}

\title{
1. Introduction
}

Polymorphism has long been the subject of great concern in the pharmaceutical and fine-chemicals industries, because polymorphs exhibit different physical and chemical properties. ${ }^{1,2}$ Particularly, the study of structure-activity relationships is of special importance in the pharmaceutical industry; an unwanted polymorph can have different bioavailability in the target organism, making the drug ineffective or rising its potency to a dangerous limit. ${ }^{2,3}$ In this context, polymorphic transformation of a metastable polymorphic form into a stable form, which very often occurs during crystallization from solvents or in the solid state, ${ }^{4-8}$ has generally been considered as an intractable phenomenon. ${ }^{1,2}$ To avoid such an undesired transformation, a lot of strategies such as the use of seed crystals and additives, and the choice of solvents and interfaces have been devised for controlling crystallization of polymorphs. ${ }^{9,10}$ In this article, we report an example of advantageous use of polymorphic transformation, i.e., an unusual symmetry-breaking enantiomeric resolution phenomenon that is initiated by the solvent-assisted solid-to-solid polymorphic transition during crystallization from the supersaturated solution of a certain kind of racemic crystals. ${ }^{11-13}$

Exploitation of economically and environmentally acceptable enantiomeric resolution methods have long been the subject of considerable interest in connection with the rationalization of the origin of biomolecular homochirality on Earth $^{14-20}$ as well as the industrial and pharmaceutical needs for chiral organic substances. ${ }^{21-25}$ Among them, the methods for enantiomeric resolution of racemates by crystallization are classified into two categories; ${ }^{26}$ one is a straightforward method to separate enantiomers in the absence of an external chiral element and the other is an indirect method using an external chiral element, such as a diastereomeric salt formation followed by fractional crystallization $^{22,27-29}$ or a diastereoselective host-guest inclusion complexation (Scheme 1). ${ }^{30}$ As the former example, since Pasteur's first manual sorting of mirror-image D and L crystals (known as racemic 'conglomerate' crystals) of a tartarate salt, ${ }^{31}$ a lot of modified methods have been devised till today for the resolution ('preferential crystallization') of racemic conglomerate crystals composed of nonracemizable enantiomers (Figure 1a) ${ }^{31-34}$ and for the deracemization of ordinary or epitaxial racemic conglomerate crystals of racemizable molecules. ${ }^{35-43}$ However, racemates existing as racemic conglomerate crystals occupy only less than $10 \%$ of the characterized crystalline racemates, and more than $90 \%$ of them are supposed to be racemic crystals ${ }^{44}$ which are further classified into (a) a 'racemic compound' consisting 
of a regular packing of a pair of $R$ and $S$ enantiomers in the crystal or (b) a racemic 'mixed crystal' (in other words, a pseudoracemate or a solid solution) composed of a random to highly-ordered arrangement of equal amounts of two enantiomers in the defined positions (Figure 2). ${ }^{11-13,26}$ A notable difference between a racemic compound and a racemic mixed crystal is that racemic crystals are exclusively formed from a racemic solution in the former type while nonracemic crystals are easily formed in the latter type. It had been believed for over a century that there was no way for resolution of these racemic crystals by simple crystallization in the absence of an external chiral element. Accordingly, if one could find out a spontaneous enantiomeric resolution phenomenon for these racemic crystals, it would provide a great impact on industrial as well as academic communities.

\section{Enantiomeric Resolution by Crystallization \\ (1) Without an external chiral element: \\ a. Preferential Crystallization (1866 )---Conglomerates \\ b. Deracemization (1980 ) ---Conglomerates \\ Attrition-enhanced Ostwald ripening (2008 ) \\ c. Preferential Enrichment (1996 )---Racemic Mixed crystal}

(2) With an external chiral element:

a. Diastereomer salt formation (1853 )---Eutectic mixture Dutch resolution (1998 )

Dielectrically controlled resolution (DCR) (2003 )

b. Diastereoselective inclusion complexation (1980 )

Scheme 1. Classification of enantiomeric resolution methods by crystallization.

(a)

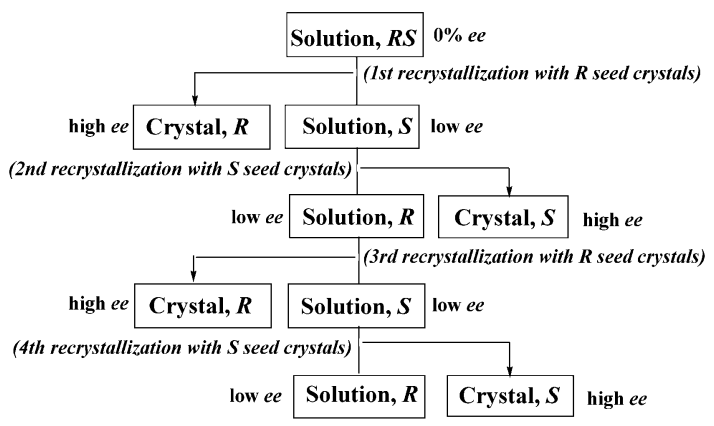

(b)
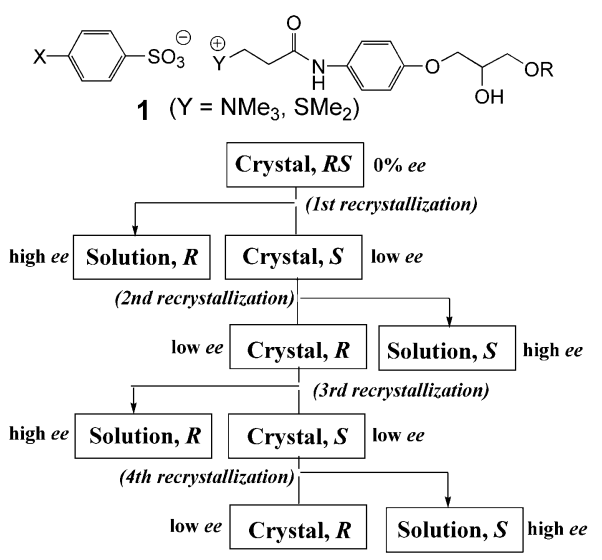

Figure 1. Principles of (a) preferential crystallization of racemic conglomerate crystals and (b) preferential enrichment of a racemic mixed crystal in the case of substantial enrichment of $R$ enantiomer in solution after first recrystallization 
of chiral organic ammonium or sulfonium sulfonate compounds $\mathbf{1}$.

\section{(a) Conglomerate}

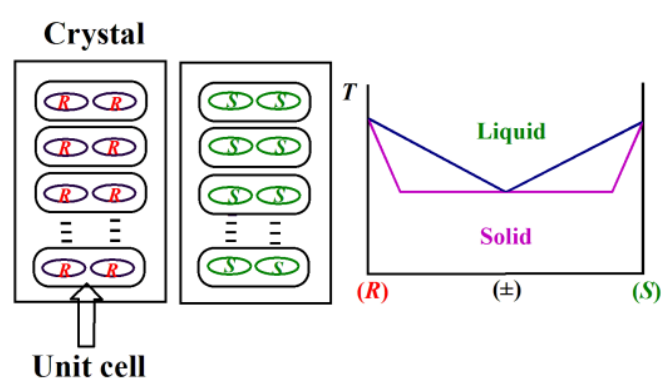

(b) Racemic Compound

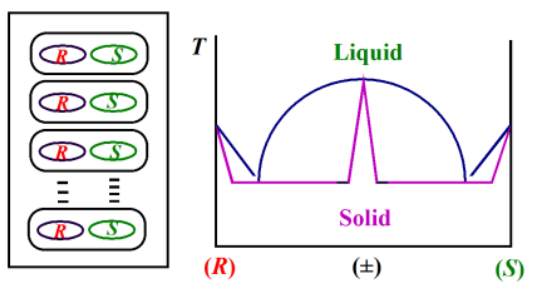

(c) Mixed Crystal

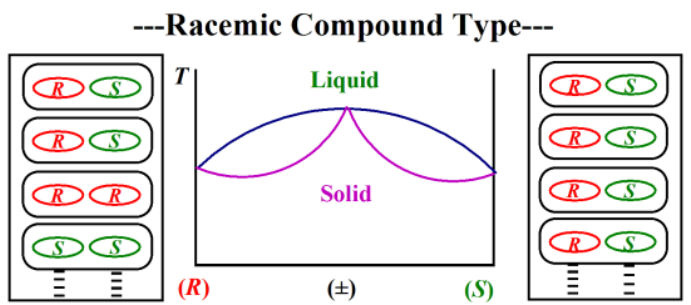

Figure 2. General packing modes and binary melting-point phase diagrams of two enantiomers in (a) racemic conglomerate crystals, (b) a racemic compound, and (c) a fairly-ordered or highly-ordered racemic mixed crystal (racemic compound type). Pink and blue lines represent the temperatures of the beginning and the end of fusion, respectively.

In 1996 we reported an unprecedented, symmetry-breaking, spontaneous enantiomeric resolution phenomenon that can be applied to certain kinds of racemic mixed crystals (Scheme 1). ${ }^{45}$ In 1998, this new phenomenon was referred to as 'preferential enrichment', ${ }^{46}$ which is completely opposed to preferential crystallization of racemic conglomerate crystals; in preferential enrichment it is in the mother liquor that substantial enantiomeric enrichment occurs by recrystallization, and at the same time slight enrichment of the opposite enantiomer always takes place in the deposited crystals (Figure 1b). In 2002, we proposed the mechanism of preferential enrichment in terms of a unique polymorphic transition during crystallization. ${ }^{47,48}$ Namely, preferential enrichment was found to be initiated by the solvent-assisted solid-to-solid transformation of a metastable polymorphic form into a thermodynamically stable one during crystallization from the supersaturated solution of certain kinds of racemic mixed crystals composed of two enantiomers without the aid of any external chiral element. ${ }^{11-13,47,48}$ Most notably, this polymorphic transition process was followed by partial crystal disintegration at incomplete hydrogen bonding sites inside the transformed crystal lattice to release the excess enantiomer into solution until the deposited crystals were slightly enriched with the opposite enantiomer $(<10 \% e e)$, with full reproducibility. ${ }^{11-13,47,48}$ Thus, the interplay of i) such a solvent-assisted solid-to-solid polymorphic transition, ii) the 
subsequent selective redissolution process of the excess enantiomer from the disintegrated crystals, and iii) the resulting deposition of mixed crystals which can retain the resulting fairly-random alignment of two enantiomers inside the crystal lattice to memorize an event of chiral symmetry-breaking, turned out to be responsible for this unique enantiomeric resolution phenomenon. ${ }^{11-13}$

Later, on the basis of the proposed mechanism of this polymorphic transition, we successfully induced and inhibited the occurrence of preferential enrichment by controlling the mode of the polymorphic transition by minor molecular modification or with appropriate seed crystals. ${ }^{49,50}$ We also observed the flexibility in the mode of polymorphic transition that could induce preferential enrichment. ${ }^{50,51}$ Furthermore, quite recently we have successfully expanded the application of the preferential enrichment phenomenon to $\alpha$-amino acids or their cocrystals with dicarboxylic acids by controlling kinetic crystallization conditions or converting a racemic compound crystal into a racemic mixed crystal, respectively. ${ }^{52,53}$ These results strongly support the propriety of our proposed mechanism of preferential enrichment. ${ }^{11-13,47,48}$ At the same time, we have recognized that preferential enrichment is ascribed to an event of a 'complexity' system that allows the chiral symmetry-breaking by a phase transition; molecular aggregation in solution, formation of metastable crystalline phases, polymorphic transition, and substantial enrichment of one enantiomer in preferential enrichment correspond to dissipative self-organization, emergence of new order and chaos, phase transition between chaos and/or order, and increasing returns in complexity, respectively. ${ }^{54-56}$

In this article, we describe the recent successful application of preferential enrichment to $\alpha$-amino acids and their cocrystals with dicarboxylic acids, together with the features, mechanism, requirements and induction (and inhibition) of preferential enrichment.

\section{Features of preferential enrichment}

Figure 3 illustrates a typical example of preferential enrichment for nearly racemic 1a which is a linear asymmetric secondary alcohol containing a glycerol moiety, an amide group, and a trimethylammonium $p$-nitrobenzenesulfonate structure (Chart 1). ${ }^{47}$ This compound was synthesized from the racemic epichlorohydrin. However, the crystalline sample obtained after the final synthetic procedure was no longer racemic but contained either enantiomer in small excess. Remarkably, preferential enrichment already occurred during the final synthetic procedure. Recrystallization of thus obtained $S$-rich crystals of $2.5 \%$ ee from ethanol under 20 -fold supersaturated conditions led to substantial enrichment of the same $S$ enantiomer in the mother liquor. At the same time, slight enrichment of the opposite $R$ enantiomer occurred in the deposited crystals. Accordingly, by repeating recrystallization and filtration, alternating enrichment of two enantiomers occurred largely in the mother liquors and slightly in the deposited crystals. These are the most important and fully reproducible features of preferential enrichment. Thus, by collecting the enantiomerically enriched mother liquors with the same handedness, very efficient separation of the two enantiomers (> 96\% ee) was easily achieved. 


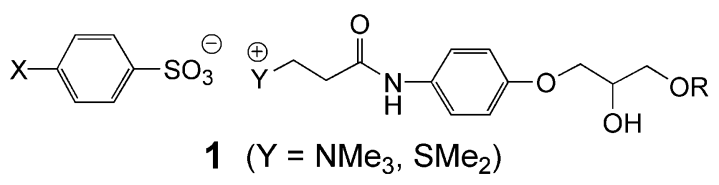

1a $X=\mathrm{NO}_{2}, \mathrm{Y}=\mathrm{NMe}_{3}, \mathrm{R}=\mathrm{C}_{2} \mathrm{H}_{5}$

1b $X=\mathrm{Br}, \quad \mathrm{Y}=\mathrm{NMe}_{3}, \mathrm{R}=\mathrm{C}_{2} \mathrm{H}_{5}$

1c $X=\mathrm{CH}_{3}, \mathrm{Y}=\mathrm{NMe}_{3}, \mathrm{R}=\mathrm{Ph}$

1d $\mathrm{X}=\mathrm{CH}_{3}, \mathrm{Y}=\mathrm{NMe}_{3}, \mathrm{R}=p-\mathrm{FC}_{6} \mathrm{H}_{4}$
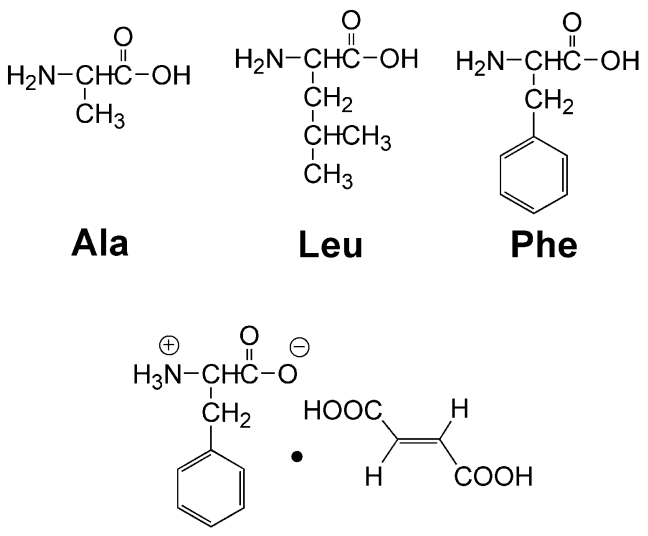

\section{1:1 Cocrystal 2}

Chart 1. Compounds described in this article.

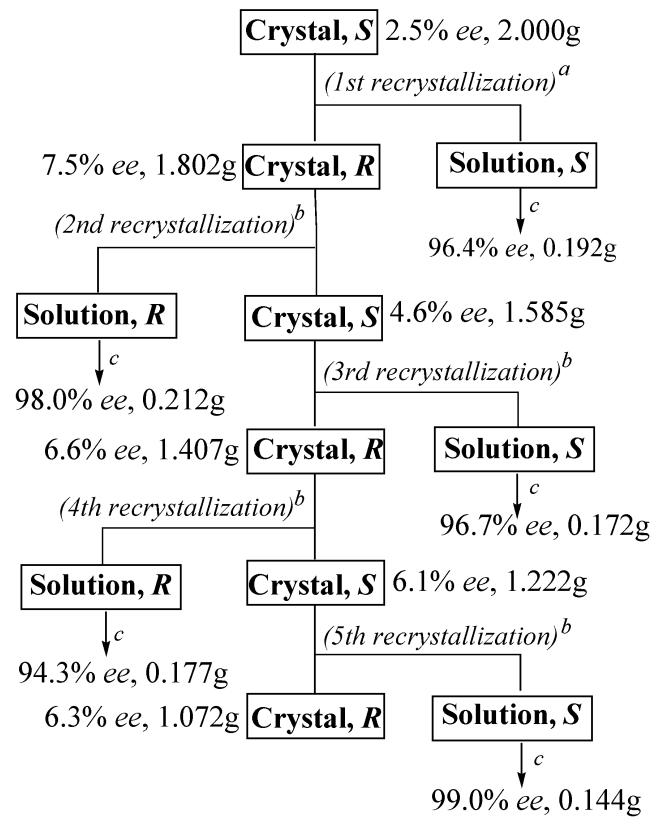

Figure 3. Features of preferential enrichment represented in the case of 1a (ref 47). Conditions: ${ }^{a} \mathrm{EtOH}(32 \mathrm{~mL})$ at $25^{\circ} \mathrm{C}$ for 4 days; ${ }^{b} \mathrm{EtOH}(32 \mathrm{~mL})$ at $25^{\circ} \mathrm{C}$ for 2 days; ${ }^{c}$ removal of the solvent by evaporation.

\section{Mechanism and requirements in the case of compounds 1}

The mechanism of preferential enrichment and the requirements for its occurrence, which we unveiled with respect to compounds 1, are as follows (Figure 4): $:^{11-13,47,48}$ 

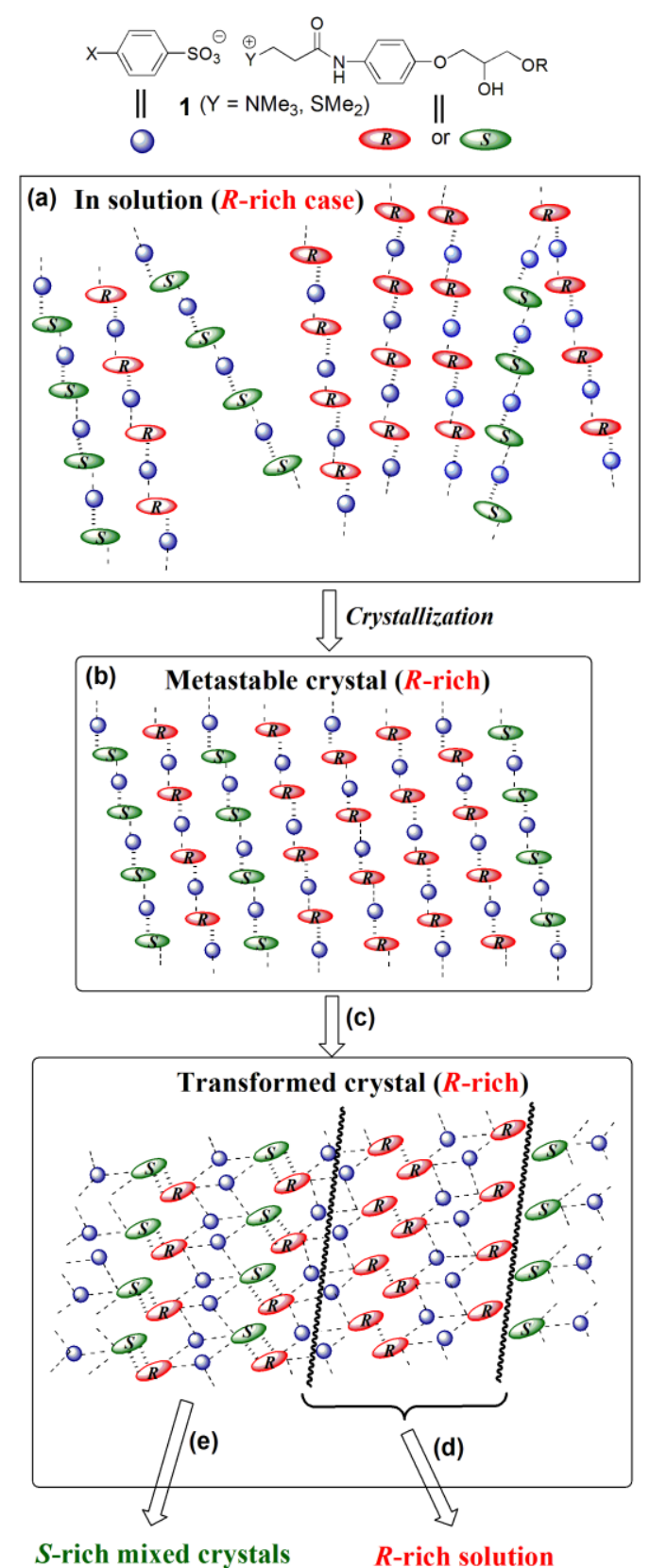

Figure 4. Mechanism of preferential enrichment in the case of crystallization from the supersaturated solution of slightly $R$-rich compounds 1. Homochiral 1D molecular association (a) in solution and (b) in the metastable crystal, (c) polymorphic transition, followed by (d) crystal disintegration and selective redissolution of the excess $R$ enantiomer into solution, and (c) deposition of nonracemic mixed crystals enriched with the opposite $S$ enantiomer.

(1) Sufficient Solubility Difference: The solubility of the enantiomerically pure sample should be much higher than that of the corresponding racemic sample; this implies the high possibility of preferential formation of homochiral one-dimensional (1D) $R$ and $S$ chains even in a racemic solution (Figure 4a). Such a solubility difference substantially affects the $e e$ value reached in the mother liquor after crystallization; the larger the difference is, the higher the reached $e e$ value in the mother liquor is. Furthermore, the combined use of supersolubility (a solubility obtained by dissolving the sample in a solvent on heating followed by being cooled) measurements under various conditions and number-averaged molecular weight measurement by vapor pressure osmometry, together with the 
molecular dynamics simulation of the oligomer models, supported a homochiral 1D assembly in preference to a heterochiral one in the racemic solutions of 1 showing preferential enrichment. ${ }^{47}$

(2) Unique Crystal Structure \& Polymorphic Transition: A solid-to-solid polymorphic transition of the initially-formed metastable mixed crystals composed of the random alignment of the homochiral 1D $R$ and $S$ chains into the stable mixed crystals mainly comprising heterochiral $R S$ cyclic dimer chains should occur during crystallization (Figure $4 \mathrm{~b}, \mathrm{c})$. This polymorphic transition that is the essence of chiral symmetry breaking can be monitored by in situ ATR-IR spectroscopy; if there is a distinct difference in the vibrations of hydrogen bond forming groups between the highly supersaturated solution just before crystallization and the deposited crystals after crystallization, polymorphic transition is most likely to occur. ${ }^{47}$

(a)

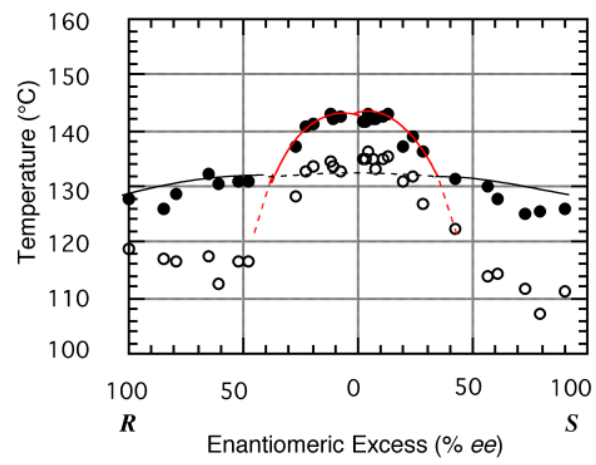

(b)

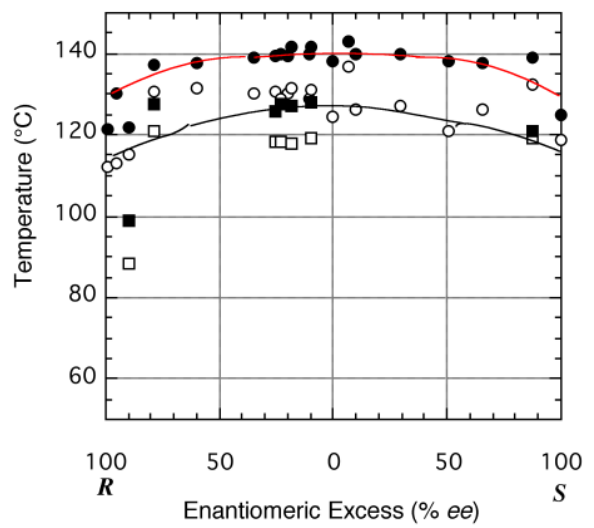

Figure 5. Melting point diagrams. (a) 1a and (b) 1b. White and black circles as well as white and black squares represent the temperatures of the beginning and the end of fusion, respectively. Red curves correspond to the stable polymorph, while black curves belong to the metastable one.

The occurrence of polymorphic transition during crystallization was further supported by two different types of unique melting point diagrams obtained experimentally for two typical compounds (1a and 1b) showing preferential enrichment. In the case of 1a, two polymorphic curves were found to intersect at two points around 35\% $e e$ (Figure 5a). The X-ray crystallographic analyses indicated that the curve in the range of 0-15\% ee corresponds to a highly- or fairly-ordered racemic or nonracemic mixed crystal, respectively. ${ }^{47}$ On the other hand, the overall flat curve in the range of more than $40 \%$ ee proved to correspond to a less-ordered nonracemic mixed crystal composed of different amounts of the $R$ and $S$ enantiomers in the crystal lattice. In the case of $\mathbf{1 b}$, there are two polymorphic convex curves which do not intersect but are located closely to each other (Figure 5b); the upper one proved to belong to a fairly-ordered racemic or nonracemic mixed crystal by X-ray crystallographic analyses, and the other corresponds to a metastable crystalline phase that suddenly disappeared prior to its characterization and was never observed again. ${ }^{57}$ From these two diagrams, the following three conclusions were obtained; i) their crystalline nature falls into a racemic or nonracemic mixed crystal, ii) there must be two polymorphic phases in both cases, and iii) the free energy difference between the two polymorphs is small enough to allow a polymorphic transition to proceed at a moderate rate during crystallization.

Thus far, four different types of stable crystal structures, $\alpha_{-}, \alpha_{1^{-}}, \delta$ - and $\varepsilon$-forms, which were classified as a highly- or fairly-ordered racemic mixed crystal, have been obtained for the racemic or nearly racemic samples of the 
compounds 1 showing preferential enrichment. In case of the $\varepsilon$-form, both crystal structures of a metastable form $(\gamma$-form) and the stable form ( $\varepsilon$-form) were solved by X-ray crystallographic analysis and by the direct-space approach employing the Monte Carlo method with the subsequent Rietveld refinement from the powder X-ray diffraction data, respectively, permitting us to suggest the mechanism of a solid-to-solid polymorphic transition occurring during crystallization. ${ }^{48}$ Among these four crystal forms, the $\delta$-form and $\alpha_{1}$-form were most commonly found for the compounds showing preferential enrichment, ${ }^{46-51,57-70}$ while only one case was observed for each of the $\alpha$-form and $\varepsilon$-form. ${ }^{45,47,48,64}$ Accordingly, described below is the mode of polymorphic transition of a $\gamma$-form polymorph into a $\delta$-form or $\alpha_{1}$-form polymorph as well as their unique crystal structures (Figure 6 ). In all of these four cases, polymorphic transition is most likely to be initiated by rearrangement of the hydrogen bonds inside the $\gamma$-form crystal lattice. The nearest $R$ and $S$ molecules in the two adjacent chains of the $\gamma$-form polymorph generate new hydrogen bonds by slight movement of the two molecules inside the crystal lattice, either between the hydroxy group and the alkoxy oxygen atom to give a cyclic dimer of type A (Figure $6 \mathrm{~b}$, transition $\boldsymbol{a})^{47}$ or between the hydroxy group and the carbonyl oxygen atom to give a cyclic dimer of type C (Figure 6c, transition $\boldsymbol{b}$ ). ${ }^{50,51}$ The $\gamma$ to $\alpha_{1}$ transition $\boldsymbol{b}$ occurs because the terminal phenoxy group prevents the $\gamma$ to $\delta$ transition $\boldsymbol{a}$ due to the steric hindrance. Subsequently, this rearrangement of hydrogen bonds, accompanied by slight movement of the phenylsulfonate group so as to form cyclic dimers of type A or C, occurs one after another in the crystal lattice and leads to the heterochiral 1D chains and then a weak 2D sheet structure (Figures 4c). The resulting 2D sheet interacts with adjacent 2D sheets through weak electrostatic interactions so as to form a loosely packed crystal structure, which can allow a partial crystal disintegration to occur inside the $2 \mathrm{D}$ sheets.

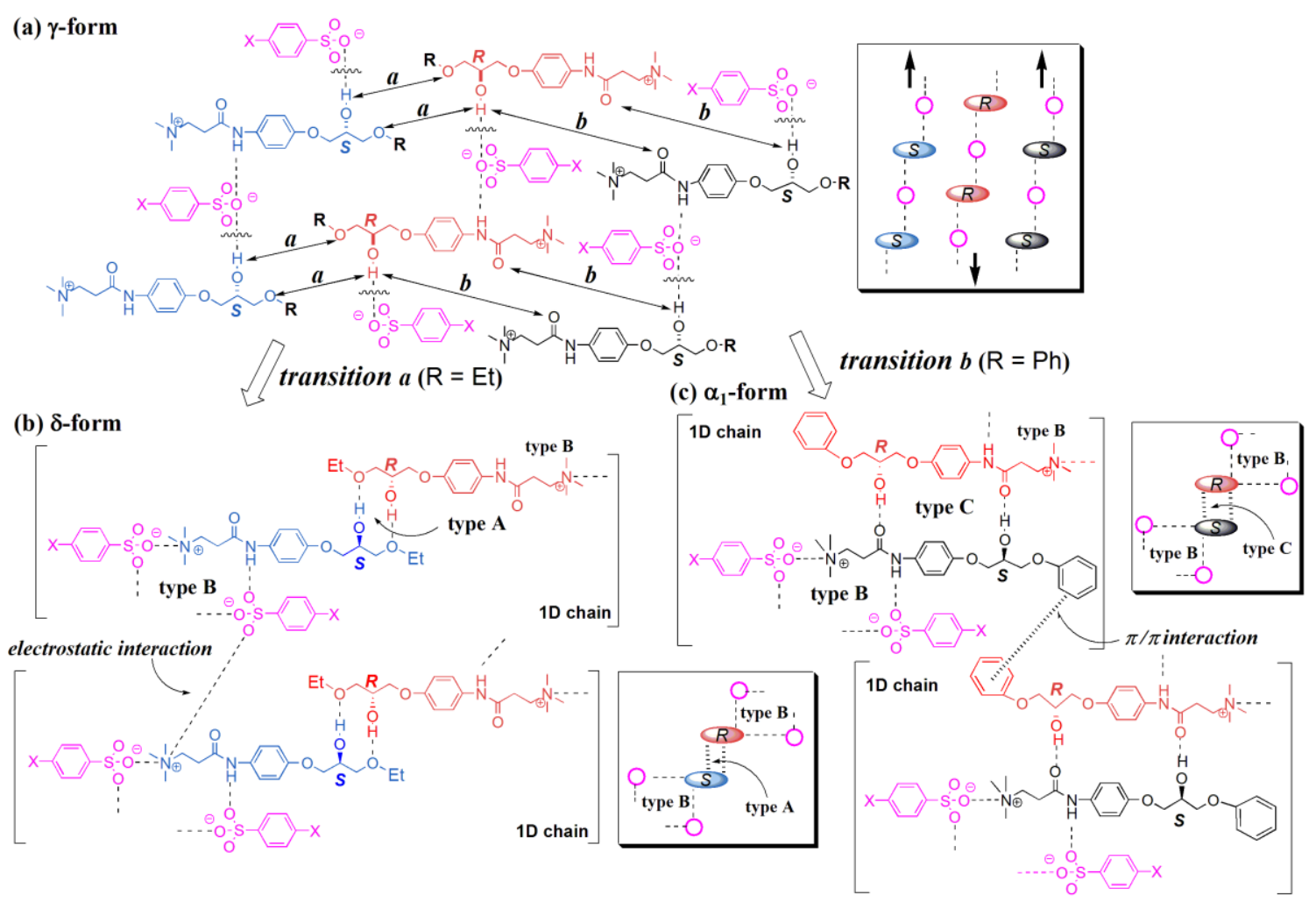

Figure 6. The mode of polymorphic transition of (a) a $\gamma$-form polymorph into (b) a $\delta$-form or (c) $\alpha_{1}$-form polymorph. The arrows $\boldsymbol{a}$ and $\boldsymbol{b}$ indicate the sites of the formation of new hydrogen bonds upon the $\gamma$-to- $\delta$ or $\gamma$-to- $\alpha_{1}$ transition, respectively. 
(3) Partial Crystal Disintegration: After the above polymorphic transition, the transformed crystals become fragile due to the incomplete hydrogen bond formation which results from the irregular alignment of $R$ and $S$ chains in the metastable $\gamma$-firm crystal lattice. Consequently, partial crystal disintegration occurs in the transformed crystals to release the excess enantiomer selectively into solution until the deposited crystals were slightly enriched with the opposite enantiomer (Figure 4d). In fact, we could visually observe a lot of convective streams evolved from the surface of the deposited crystals for 90 min at the beginning of crystallization of nearly racemic 1a from ethanol at $25^{\circ} \mathrm{C}$ (Figure 7). ${ }^{47}$ These streams were found to be enriched by one enantiomer which dissolved from the just-made crystals into solution, resulting in enrichment of the same enantiomer in the mother liquor. This process is closely associated with the higher solubility of the enantiomerically pure sample.
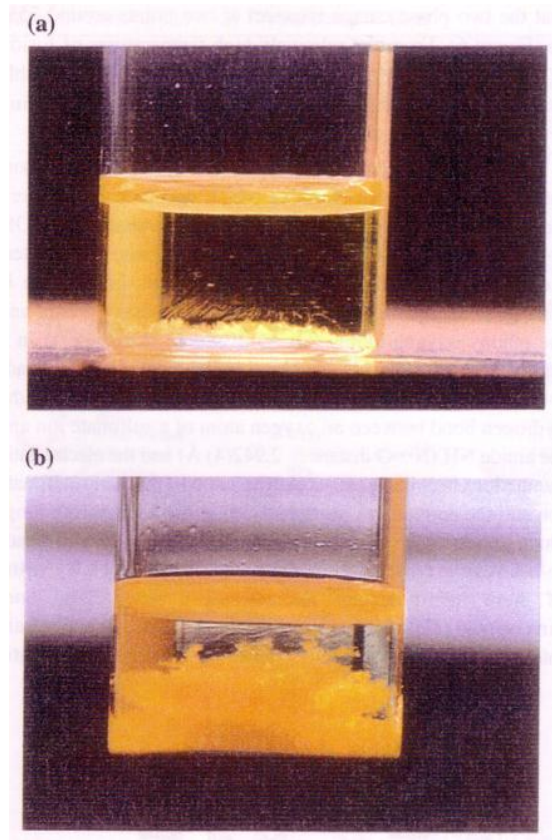

Figure 7. Visual observation of polymorphic transition and redissolution of one enantiomer from the once formed crystals during crystallization from the supersaturated EtOH solution of nearly racemic 1a (ref 47) (a) 15 min and (b) 60 min after crystallization began.

(4) Deposition of Nonracemic Mixed Crystals: The resulting deposited nonracemic mixed crystals should not undergo the subsequent solvent-mediated polymorphic transition that may give exactly racemic crystals of $0 \% e e$ and thereby decrease the ee value in solution, memorizing the event of chiral symmetry breaking (Figure 4e).

Accordingly, the technical and phenomenal features of preferential enrichment are summarized as follows: ${ }^{11-13,47}$

1) Usual standard recrystallization conditions with neither vigorous stirring nor abrasive grinding are applied to the preferential enrichment experiment, except that approximately 4- to 25-fold supersaturated solutions are employed because the supersolubility of the racemates showing preferential enrichment is considerably higher than that of the solubility at $25^{\circ} \mathrm{C}$. The attainment of such a high supersolubility is closely associated with the preferential formation 
of homochiral 1D $R$ and $S$ chains even in the racemic solution. At the supersaturated concentrations lower than 4-fold, preferential enrichment does not efficiently occur.

2) Racemic or nonracemic samples of less than $10 \%$ ee are more suitable for the preferential enrichment experiment than those of higher ee values to achieve a very efficient resolution, resulting in the deposition of nonracemic crystals slightly enriched (around 5\% ee) with the opposite enantiomer.

3) When the original supersaturated solution used for crystallization is strictly racemic $(0.0 \% e e)$, the probability for either the $R$ or the $S$ enantiomer to be enriched in the mother liquor after crystallization is 0.5 . This is because initial capricious formation of the very first nonracemic metastable crystal nucleus should determine which enantiomer is enriched in the mother liquor later.

4) Only racemic or nonracemic samples have to be crystalline to implement the preferential enrichment experiment efficiently. It does not matter whether the enantiomerically enriched samples with high $e e$ values exist as solids or oils, in sharp contrast to preferential crystallization of racemic conglomerate crystals.

5) Seed crystals are not necessary at all.

\section{Control of polymorphic transition of compounds 1}

Preferential enrichment is strongly affected by the surrounding conditions, such as seed crystals or additives, solvent, concentration and temperature, as well as the molecular structure. ${ }^{11-13}$ In this section, two complimentary strategies are described for the induction of preferential enrichment by controlling the mode of polymorphic transition. One is the slight modification of the molecular structure so as to prevent the undesired polymorphic transition, and the other is the use of the appropriate seed crystals to induce the desired polymorphic transition, i.e., 'epitaxial transition' phenomenon. ${ }^{49,50}$ As typical examples of these strategies, let us focus on the racemic samples of two structurally analogous ammonium sulfonates $\mathbf{1 c}(\mathrm{X}=\mathrm{Me}, \mathrm{R}=\mathrm{Ph})$ and $\mathbf{1 d}\left(\mathrm{X}=\mathrm{Me}, \mathrm{R}=p-\mathrm{FC}_{6} \mathrm{H}_{4}\right)(\mathrm{Chart} 1){ }^{50}$

(1) Slight modification of molecular structure

Crystallization of $( \pm)$-1c from EtOH gave the undesired $\mu$-form deposited crystals and thereby failed to show preferential enrichment, while the terminal $p$-fluorophenoxy analogue $( \pm)$-1d gave the desired $\alpha_{1}$-form crystals by crystallization from EtOH and showed preferential enrichment. The crystal structure of the $\mu$-form of $( \pm)$-1c with a heterochiral 2D sheet structure is quite different from that of $\alpha_{1}$-form which is mainly composed of heterochiral cyclic $R S$ dimer chains (Figures 6 and 8). The partial crystal disintegration inside the crystal lattice necessary for the occurrence of preferential enrichment seems impossible in this robust $\mu$-form crystal structure of ( \pm )-1c. Therefore, it was concluded that for $( \pm)$-1c the direct transformation of the $\gamma$-form into the $\mu$-form occurred without the intermediary of the $\alpha_{1}$-form. 


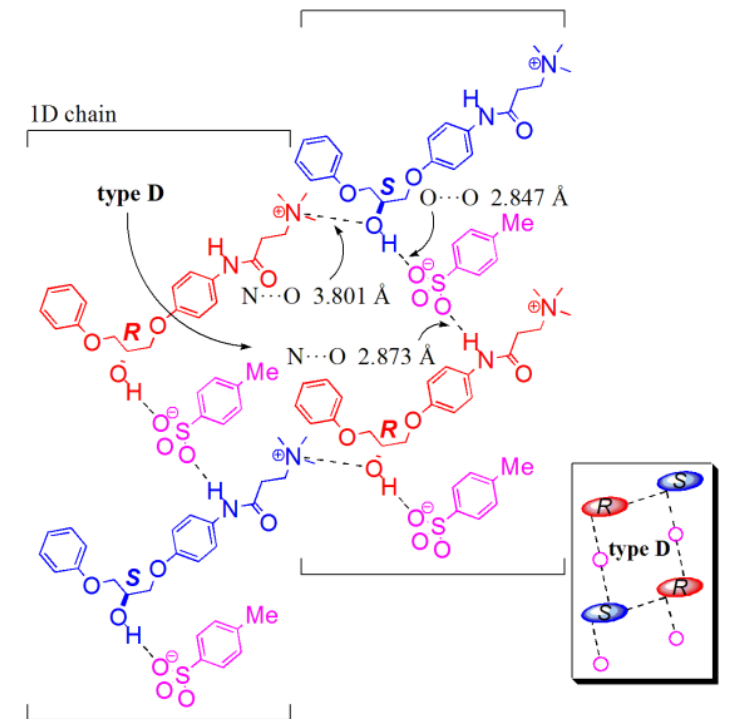

Figure 8. Schematic representation of the crystal structure of the $\mu$-form of $( \pm)-\mathbf{1 c}$.

(2) Induction and inhibition by epitaxial transition

It has been shown that both induction and inhibition of preferential enrichment could be accomplished by controlling the mode of the polymorphic transition during crystallization with appropriate seed crystals, on the basis of the 'epitaxial transition' phenomenon that consists of 1) the adsorption of $\gamma$-form prenucleation aggregates, 2) the heterogeneous nucleation and crystal growth of a metastable $\gamma$-form polymorph, and 3) the subsequent polymorphic transition into the more stable ones such as $\delta$ - and $\alpha_{1}$-forms, on the same surface of a seed crystal (Figure 9). ${ }^{49,50}$

As an example of induction, addition of the $\alpha_{1}$-form seed crystals of ( \pm )-1d (Figure 6), which could easily show preferential enrichment, to the supersaturated EtOH solution of $( \pm)-\mathbf{1 c}$, which did not show this phenomenon by itself due to the undesired polymorphic transition of the $\gamma$-form into the more stable $\mu$-form, could explicitly induce the preferential enrichment of ( \pm )-1c, accompanied by the deposition of the $\alpha_{1}$-form crystals of $( \pm)$-1c. On the other hand, as expected, addition of the $\mu$-form seed crystals of $( \pm)$-1c to the supersaturated EtOH solution of $( \pm)$-1d inhibited the preferential enrichment of ( \pm )-1d completely, resulting in the deposition of $\mu$-form crystals of $( \pm)$-1d. Furthermore, the same $\alpha_{1}$-form seed crystals of $( \pm)$-1d inhibited the occurrence of preferential enrichment of $( \pm)-\mathbf{1 d}$ itself, due most likely to the quick crystallization of the $\alpha_{1}$-form without the intermediary of the $\gamma$-form from the supersaturated solution.
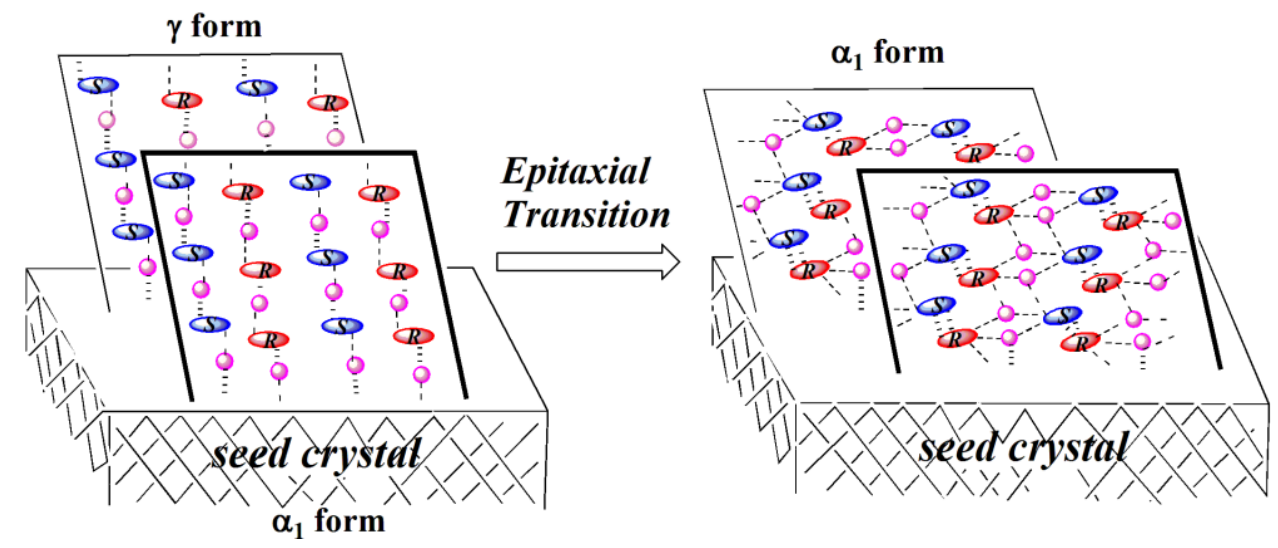

Figure 9. Schematic representation of epitaxial transition of a metastable $\gamma$-form polymorph into an $\alpha_{1}$-form on the surface of $\alpha_{1}$-form seed crystal. 
These experimental results obtained by two strategies strongly support the propriety of our proposed mechanism of preferential enrichment in which the polymorphic transition of the initially formed $\gamma$-form polymorph into the $\alpha_{1}$-form polymorph is an essential process for the occurrence of preferential enrichment of $( \pm)$-1c and $( \pm)$-1d (Figure 4).

\section{Application to $\alpha$-amino acids}

We speculated that a racemic compound with a high eutectic ee value might behave like a racemic mixed crystal under nonequilibrium crystallization conditions (Figure 10). Furthermore, it was anticipated that if the four requirements (sufficient solubility difference, unique crystal structure \& polymorphic transition, partial crystal disintegration, deposition of nonracemic mixed crystals) for the occurrence of preferential enrichment described in section 3 were satisfied, preferential enrichment might occur for a racemic compound with a high eutectic ee value under nonequilibrium crystallization conditions. Such indeed has been the case. Here we describe the preferential enrichment observed for neutral $\alpha$-amino acids such as alanine (Ala) and leucine (Leu), ${ }^{52}$ and a cocrystal of phenylalanine (Phe) and fumaric acid, ${ }^{53}$ which are traditionally classified as a racemic compound.
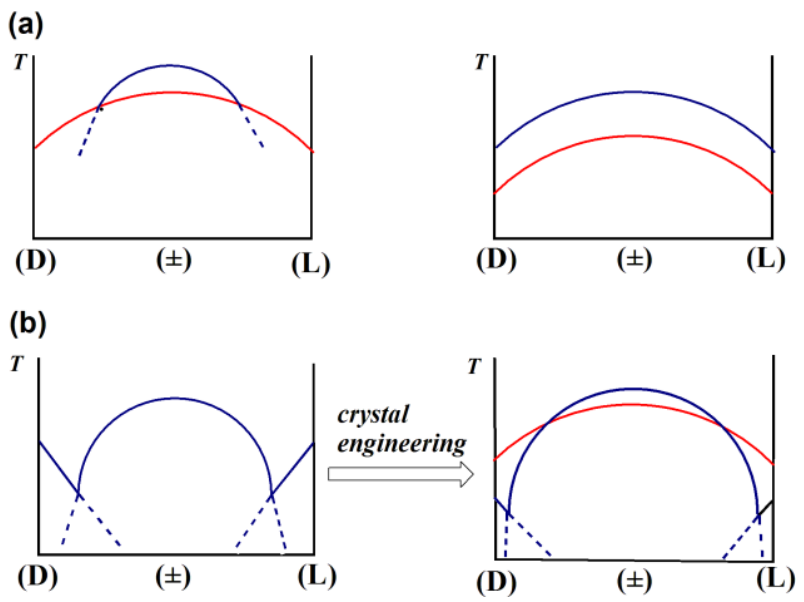

Figure 10. Melting point diagrams with a polymorphism essential to induce preferential enrichment (ref 53). a) Two typical diagrams of a racemic mixed crystal capable of showing preferential enrichment with respect to compounds $\mathbf{1}$ (ref 11-13). b) A concept of transforming of a common racemic compound into a racemic mixed crystal (or another racemic compound with a high eutectic ee value) with an appropriate polymorphism by crystal engineering. For clarity, only the temperatures of end of fusion are shown. Red and blue curves correspond to the metastable and stable polymorphs, respectively, near the racemic composition.

(1) Ala and Leu ${ }^{52}$

We searched for neutral $\alpha$-amino acids with moderate to high eutectic ee values that could satisfy the above four requirements for the occurrence of preferential enrichment. Consequently, the enantiomerically pure samples of Ala, Leu, methionine (Me), Phe, serine (Ser), and proline (Pro) showed higher solubility than the corresponding racemic samples in the mixed solvents of $\mathrm{H}_{2} \mathrm{O}$ and $\mathrm{EtOH}$, which later turned out to be an appropriate solvent system for the preferential enrichment of Leu and Ala (Chart 1). Among these six amino acids, only Ala and Leu exhibited the occurrence of polymorphic transition during crystallization, which was monitored by in situ ATR-IR spectroscopy. Furthermore, the crystal structures of $( \pm)$-Ala and $( \pm)$-Leu are composed of alternating homochiral 1D D and L chains 
and heterochiral DL cyclic dimer chains, respectively. Eventually, Ala and Leu with moderate and high eutectic ee values (56\% and $86 \%)$ in water, respectively, exhibited preferential enrichment under nonequilibrium crystallization conditions using high concentrations in aqueous solvents (Figure 11), although the efficiency of resolution was very low due to the nature of the deposited crystals. The crystals of Ala deposited under the preferential enrichment conditions were nonracemic mixed crystals, while those of Leu were mostly achiral nonracemic lamellar twin crystals. Accordingly, the lamellar twin crystals turned out to behave like the mixed crystals of two enantiomers which can retain the fairly random arrangement of two enantiomers and allow the redissolution of excess enantiomer in the once formed crystals into solution.
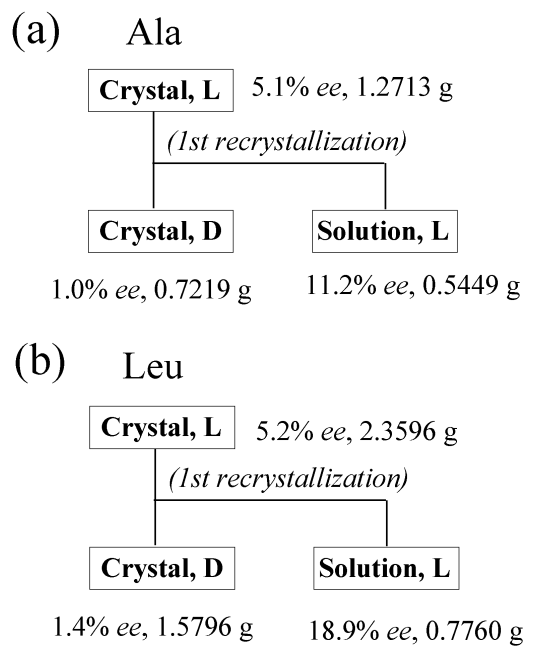

Figure 11. Preferential enrichment of (a) Ala and (b) Leu (ref 52). Conditions: $\mathrm{H}_{2} \mathrm{O}-\mathrm{EtOH}\left(\mathrm{v} / \mathrm{v} 1: 1,38.6 \mathrm{~mL}\right.$ ) at $15^{\circ} \mathrm{C}$ for 7 days for Ala and $\mathrm{H}_{2} \mathrm{O}-\mathrm{EtOH}(\mathrm{v} / \mathrm{v} 1: 1,310 \mathrm{~mL})$ at $25^{\circ} \mathrm{C}$ for 3 days for Leu.

Thus, preferential enrichment turned out to be applicable to racemic compound crystals by carefully choosing kinetic crystallization conditions so as to induce a polymorphic transition.

(2) 1:1 Cocrystal (2) of (DL)-Phe and fumaric acid ${ }^{53}$

Since a two-component cocrystal has a high potential of showing a polymorphism and inducing polymorphic transition during crystallization, ${ }^{71}$ we have carried out an extensive search from the Cambridge Structural Database (CSD) with respect to the cocrystal of a racemic $\alpha$-amino acid and an achiral carboxylic acid as the model compound which has the desired crystal structure for the occurrence of preferential enrichment. Consequently, we have found that the 1:1 cocrystal (2) of (DL)-Phe and fumaric acid (Chart 1), which has a eutectic ee value of as high as $99 \%$ in water, ${ }^{72}$ satisfies all of the above requirements and indeed shows an efficient preferential enrichment phenomenon (Figure 12), whereas a racemic compound (DL)-Phe itself fails to show a polymorphic transition and thereby preferential enrichment. The crystals of $\mathbf{2}$ deposited under the preferential enrichment conditions were nonracemic mixed crystals of around 5\% $e e$. The powder X-ray diffraction pattern of the nonracemic deposited crystals was identical to that simulated from the X-ray crystallographic data of the single DL-cocrystal 2 of $0 \%$ ee (Figure 13). ${ }^{72}$ 


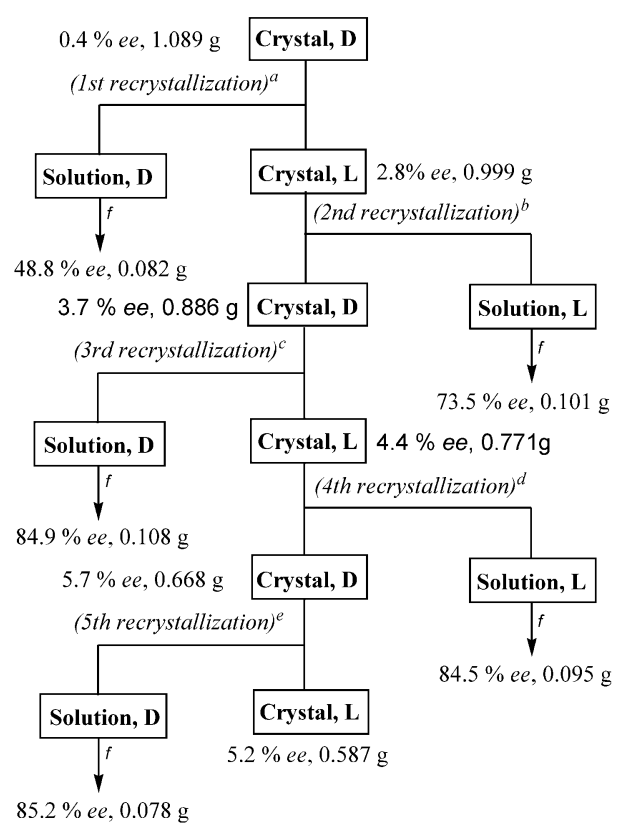

Figure 12. Preferential enrichment of cocrystal 2 (ref 53). Conditions: ${ }^{\mathrm{a}} \mathrm{H}_{2} \mathrm{O}\left(10.0 \mathrm{~mL}, 6\right.$-fold supersaturation) at $5{ }^{\circ} \mathrm{C}$ for $60 \mathrm{~h} ;{ }^{\mathrm{b}} \mathrm{H}_{2} \mathrm{O}(9.2 \mathrm{~mL})$ at $5{ }^{\circ} \mathrm{C}$ for $48 \mathrm{~h} ;{ }^{\mathrm{c}} \mathrm{H}_{2} \mathrm{O}(8.7 \mathrm{~mL})$ at $5{ }^{\circ} \mathrm{C}$ for $42 \mathrm{~h} ;{ }^{\mathrm{d}} \mathrm{H}_{2} \mathrm{O}(7.8 \mathrm{~mL})$ at $5{ }^{\circ} \mathrm{C}$ for $24 \mathrm{~h} ;{ }^{\mathrm{e}} \mathrm{H}_{2} \mathrm{O}(6.9 \mathrm{~mL})$ at $5{ }^{\circ} \mathrm{C}$ for $24 \mathrm{~h} ;{ }^{\mathrm{f}}$ removal of the solvent by evaporation.

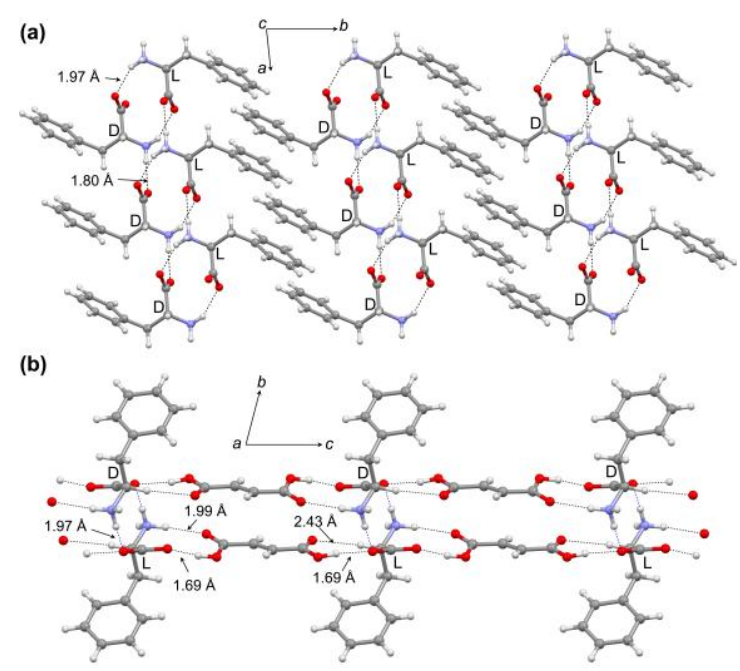

Figure 13. Crystal structure of DL-cocrystal 2 (ref 53). (a) A view down the $c$-axis. Fumaric acid molecules were omitted for clarity. (b) A view down the $a$-axis. The carbon, oxygen, nitrogen, and hydrogen atoms are represented by grey, red, blue, and white circles, respectively.

On the basis of these experimental results and the proposed mechanism of preferential enrichment with respect to compounds 1, ${ }^{11-13,47-51}$ the observed preferential enrichment phenomenon of cocrystal $\mathbf{2}$ can be interpreted in terms of the following successive processes (in case of using a slightly L-rich sample) (Figure 14a); (i) preferential formation of homochiral 1D D and L chains of type A in the slightly L-rich solution, (ii) a solid-to-solid polymorphic transition of the metastable, slightly L-rich mixed crystals composed of the same homochiral D and L chains of type A into the stable, slightly L-rich mixed crystals mainly composed of heterochiral cyclic dimer chains of type B, and (iii) partial crystal disintegration in the irregular molecular alignment area, where an even number of homochiral L chains (four in 
this case) are surrounded by two D chains before polymorphic transition, inside the transformed crystal lattice to selectively release the excess L enantiomer into solution until the deposited crystals are slightly enriched with the opposite D enantiomer $(<6 \% e e)$, resulting in the generation of crystal defects incapable of undergoing crystal growth any longer. In analogy with the case of preferential enrichment of compounds $\mathbf{1},{ }^{11-13,47}$ this crystal disintegration should occur at the incomplete dimer sites on the $a c$-plane due to the presence of weakened hydrogen bond $[d / l(\mathrm{O}---\mathrm{N}$ distance: $3.474 \AA$ ) vs D/L (O---N distance: $2.871 \AA$ )] between the carboxylate oxygen atom and the ammonium group, which arises from the positional disorder of the two enantiomers (Figures 14b,c).

\section{(a)}
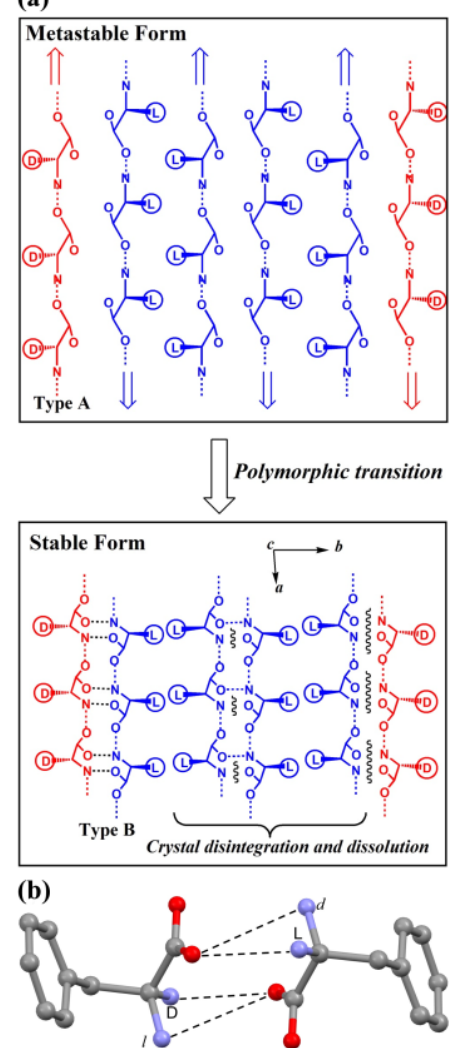

(c)

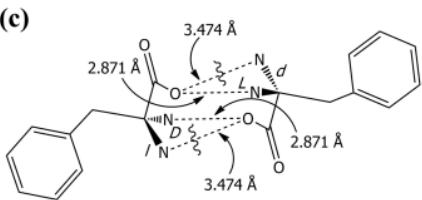

Figure 14. The proposed mode of polymorphic transition of racemic or nonracemic cocrystal 2 (ref 53). (a) Transformation of a metastable form into a stable one. This is the case in which an even number (four in this case) of homochiral L chains are surrounded by two D chains in the metastable form, resulting in partial crystal disintegration after polymorphic transition. (b) Hypothetical type B cyclic dimer chain structure in the cocrystal 2 with orientational disorder at the position of the amino group on an asymmetric carbon atom. (c) Schematic illustration of panel b.

Although we also prepared the cocrystals of other neutral $\alpha$-amino acids such as Ala, Ile, Leu, Met, Ser, Tyr and Val with fumaric acid, they did not exhibit a polymorphic transition during crystallization and hence failed to show preferential enrichment. However, it is expected that co-crystallization with other acids may provide a chance of finding a system to induce preferential enrichment. 


\section{Conclusions}

The mechanism of preferential enrichment has been interpreted in terms of a symmetry-breaking complexity phenomenon including two major elements; (1) the polymorphic transition of an incipient metastable crystalline form into the more stable one and (2) the dissolution of the excess enantiomer from the transformed crystals into solution, resulting in a considerable enrichment of the excess enantiomer in the mother liquor until a slight enrichment of the opposite enantiomer in the deposited crystals occurs. Therefore, preferential enrichment is not only an excellent chiral separation phenomenon but also a good research model for a complexity phenomenon.

Successful induction of preferential enrichment, based on the concept "epitaxial transition", strongly support the propriety of our proposed mechanism of preferential enrichment. If the crystal lattices and crystal structures of the two compounds are partly similar to each other, it is possible to control the mode of polymorphic transition mutually by seeding with each other. Accordingly, once one finds a leading racemic sample that can show preferential enrichment, it is possible to induce preferential enrichment for analogous compounds that cannot show preferential enrichment by themselves, on the basis of this epitaxial transition protocol.

Furthermore, preferential enrichment is applicable to so-called racemic compound crystals, if the five requirements (high eutectic ee value, sufficient solubility difference, unique crystal structure \& polymorphic transition, partial crystal disintegration, deposition of nonracemic mixed crystals) described in this article are satisfied. For example, a racemic compound (DL)-Phe, which did not show preferential enrichment by itself, could be persuaded to exhibit this phenomenon by co-crystallizing it with fumaric acid; the crystal engineering principles greatly contribute to produce the requisite molecular arrangement which can induce an appropriate polymorphic transition during crystallization. Therefore, it is of great advantage to use a two-component cocrystal to induce preferential enrichment, because a solid-to-solid polymorphic transition involving a molecular rearrangement or a rearrangement of hydrogen bonds in the crystal lattice is essential. We believe that preferential enrichment should become a potent enantiomeric resolution method for other racemic compound crystals such as chiral drugs in company with the further development of kinetic crystallization technologies.

\section{References}

1 J. Bernstein, Polymorphism in Molecular Crystals, Oxford University Press, Oxford, 2002.

2 Polymorphism in Pharmaceutical Solids, ed. H. G. Brittain, Marcel Dekker, New York, 1999.

3 J. Lu, S. Rohani, Curr. Med. Chem., 2009, 16, 884.

4 D. Croker, B. K. Hodnett, Cryst. Growth Des., 2010, 10, 2806.

5 D. Mangin, F. Puel, S. Veesler, Org. Process Res. Dev., 2009, 13, 1241.

6 S. Wishkerman, J. Bernstein, Chem. Eur. J., 2008, 14, 197.

7 G. T. Beckham, B. Peters, C. Starbuck, N. Variankaval, B. L. Trout, J. Am. chem.. Soc., 2007, 129, 4714.

8 F. H. Herbstein, Acta Cryst., 2006, B62, 341

9 I. Weisbuch, L. Leiserowitz, M. Lahav, Crystallization Technology Handbook, ed. A. Mersmann, Marcel Dekker, New York, 1995, pp.401-457.

10 M. Kitamura, CrystEngComm., 2009, 11, 949.

11 R. Tamura, H. Takahashi, D. Fujimoto, T. Ushio, Top. Curr. Chem., 2007, 269, 53. 
R. Tamura, S. Iwama, H. Takahashi, Symmetry, 2010, 2, 112.

R. Tamura, T. Ushio, Enantiomer Separation: Fundamentals and Practical Methods, ed. F. Toda, Kluwer Academic Publishers, Dordrecht, The Netherlands, 2004, pp. 135-163.

D. G. Blackmond, M. Klussmann, Chem. Commun., 2007, 3990.

D. G. Blackmond, Chem. Eur. J., 2007, 13, 3290.

P. Cintas, Angew. Chem. Int. Ed., 2002, 41, 1139.

M. Quack, Angew. Chem. Int. Ed., 2002, 41, 4618.

M. Avalos, R. Babiano, P. Cintas, J. L. Jimenez, J. C. Palacios, Chem Commun., 2000, 887.

H. Bushmann, R. Thede, D. Heller, Angew. Chem. Int. Ed., 2000, 39, 4033.

J. Podlech, Angew. Chem. Int. Ed., 1999, 38, 477.

Chiral Separations: Methods and Protocols, ed. G. Gubitz, M. G. Schmid, Humana Press, 2004.

CRC Handbook of Optical Resolutions via Diastereomeric Salt Formation, ed. D. Kozma, CRC Press, Boca Raton, FL, 2001.

Chiral Separation Techniques, ed. G. Subramanian, Wiley-VCH, Weinheim, 2001.

Handbook of Chiral Chemicals, ed. D. J. Ager, Marcel Dekker, New York, 1999.

Chirality in Industry II; ed. A. N. Collins, G. N. Sheldrake, J. Crosby, Wiley, New York, 1997.

J. Jacques, A. Collet, A.S. H. Wilen, Enantiomers, Recemates and Resolutions, Krieger, Malabar, FL, 1994.

K. Kinbara, K. Saigo, Top. Stereochem., 2003, 23, 207-265.

K. Sakai, R. Sakurai, H. Nohira, Top. Curr. Chem., 2007, 269, 199.

R. M. Kellogg, B. Kaptein, T. R. Vries, Top. Curr. Chem., 2007, 269, 159.

F. Toda, Enantiomer Separation: Fundamentals and Practical Methods, ed. F. Toda, Kluwer, Dordrecht, The Netherlands, 2004, pp. 1- 47.

31 L. Pasteur, Ann. Chim. Phys., 1848, 24, 442.

32 A. Collet, A. Optical Resolution, in Comprehensive Supramolecular Chemistry, ed. D. N. Reinhoudt, Pergamon, Oxford, 1996, vol. 10, pp. 113-149.

33 K. Kinbara, Y. Hashimoto, M. Sukegawa, H. Nohira, K. Saigo, J. Am. Chem. Soc., 1996, 118, 3441.

34 G. Levilain, G. Coquerel, CrystEngComm., 2010, 12, 1983.

35 R. Yoshioka, Top. Curr. Chem., 2007, 269, 83.

36 W. L. Noorduin, T. Izumi, A. Millemaggi, M. Leeman, H. Meekes, W. J. P. van Enckevort, R. M. Kellogg, B. Kaptein, E. Vlieg, D. G. Blackmond, J. Am. Chem. Soc., 2008, 130, 1158.

37 W. L. Noorduin, H. Meekes, W. J. P. van Enckevort, A. Millemaggi, M. Leeman, B. Kaptein, R. M. Kellogg, E. Vlieg, Angew. Chem. Int. Ed., 2008, 47, 6445.

38 B. Kaptein, W. L. Noorduin, H. Meekes, W. J. P. van Enckevort, R. M. Kellogg, E. Vlieg, Angew. Chem. Int. Ed., $2008,47,7226$.

39 W. L. Noorduin, A. A. Bode, M. van der Meijden, H. Meekes, A. F. van Etteger, W. J. P. van Enckevort, P. C. M. Christianen, B. Kaptein, R. M. Kellogg, Nat. Chem., 2009, 1, 729.

40 W. L. Noorduin, H. Meeks, W. J. P. van Enckevort, B. Kaptein, R. M. Kellogg, E. Vlieg, Angew. Chem. Int. Ed., $2010,49,2539$.

41 B. S. Green, M. Knossow, Science, 1981, 214, 795-797. 
42 M. Berfeld, D. Zbaida, L. Leiserowitz, M. Lahav, M. Adv. Mater., 1999, 11, 328.

43 D. Zbaida, M. Lahav, K. Drauz, G. Knaup, M. Kottenhahn, Tetrahedron, 2000, 56, 6645

44 E. Eliel, S. H. Wilen, L. N. Mander, Stereochemistry of Organic Compounds, Wiley, New York, 1994, pp. 297-464.

45 T. Ushio, R. Tamura, H. Takahashi, K. Yamamoto, Angew. Chem. Int. Ed., 1996, 35, 2372.

46 R. Tamura, H. Takahashi, K. Hirotsu, Y. Nakajima, T. Ushio, F. Toda, Angew. Chem. Int. Ed., 1998, $37,2876$.

47 R. Tamura, D. Fujimoto, Z. Lepp, K. Misaki, H. Miura, H. Takahashi, T. Ushio, T. Nakai, K. Hirotsu, J. Am. Chem. Soc., 2002, 124, 13139.

48 D. Fujimoto, R. Tamura, Z. Lepp, H. Takahashi, T. Ushio, Cryst. Growth Des., 2003, 3, 973.

49 R. Tamura, M. Mizuta, S. Yabunaka, D. Fujimoto, T. Ariga, S. Okuhara, N. Ikuma, H. Takahashi, H. Tsue, Chem. Eur. J., 2006, 12, 3515.

50 M. Horiguchi, S. Okuhara, E. Shimano, D. Fujimoto, H. Takahashi, H. Tsue, R. Tamura, Cryst. Growth Des., 2008, 8, 540 .

51 M. Horiguchi, S. Okuhara, E. Shimano, D. Fujimoto, H. Takahashi, H. Tsue, R. Tamura, Cryst. Growth Des., 2007, 7, 1643.

52 S. Iwama, M. Horiguchi, H. Sato, Y. Uchida, H. Takahashi, H. Tsue, R. Tamura, Cryst. Growth Des., 2010,10, 2668.

53 R. G. Gonnade, S. Iwama, Y. Mori, H. Takahashi, H. Tsue, R. Tamura, Cryst. Growth Des., 2011, $11,607$.

54 K. Mainzer, Symmetry and Complexity: The Sprit and Beauty of Nonlinear Science, World Scientific, Singapore, 2005.

55 S. Kauffman, Investigations, Oxford University Press, Oxford, 2000.

56 M.M. Waldrop, Complexity, Simon \& Schuster, New York, 1992.

57 H. Takahashi, R. Tamura, D. Fujimoto, Z. Lepp, K. Kobayashi, T. Ushio, Chirality, 2002, 14, 541.

58 R. Tamura, T. Ushio, K. Nakamura, H. Takahashi, N. Azuma, F. Toda, Enantiomer, 1997, $2,277$.

59 R. Tamura, T. Ushio, H. Takahashi, K. Nakamura, N. Azuma, F. Toda, K. Endo, Chirality, 1997, 9, 220.

60 H. Takahashi, R. Tamura, T. Ushio, Y. Nakajima, K. Hirotsu, Chirality, 1998, 10, 705.

61 R. Tamura, H. Takahashi, K. Hirotsu, Y. Nakajima, T. Ushio, Mol. Cryst. Liq. Cryst., 2001, 356, 185.

62 R. Tamura, H. Takahashi, T. Ushio, Y. Nakajima, K. Hirotsu, F. Toda, Enantiomer, 1998, 3, 149.

63 R. Tamura, H. Takahashi, H. Miura, Z. Lepp, Y. Nakajima, K. Hirotsu, T. Ushio, Supramol. Chem., $2001,13,71$.

64 H. Takahashi, R. Tamura, Z. Lepp, K. Kobayashi, T. Ushio, Enantiomer, 2001, 6, 57.

65 H. Takahashi, R. Tamura, D. Fujimoto, Z. Lepp, K. Kobayashi, T. Ushio, Chirality, 2002, $14,541$.

66 H. Takahashi, R. Tamura, S. Yabunaka, T. Ushio, Mendeleev Commun., 2003, 119.

67 H. Miura, T. Ushio, K. Nagai, D. Fujimoto, Z. Lepp, H. Takahashi, R. Tamura, Cryst. Growth Des., $2003,3,959$.

68 H. Takahashi, R. Tamura, S. Yabunaka, M. Mizuta, N. Ikuma, H. Tsue, T. Ushio, Mendeleev Commun., $2004,239$.

69 D. Fujimoto, H. Takahashi, T. Ariga, R. Tamura, Chiraliry, 2006, 18, 188.

70 M. Horiguchi, S. Yanunaka, S. Iwama, E. Shimano, Z. Lepp, H. Takahashi, H. Tsue, R. Tamura, Eur. J. Org. Chem., 2008, 3496.

71 W. W. Porter III, S. C. Elie, A. J. Matzger, Cryst. Growth Des., 2008, 8, 14.

72 M. Klussmann, T. Izumi, A. J. P.white, A. Armstrong, D. G. Blackmond, J. Am. Chem. Soc., 2007, $129,7657$. 